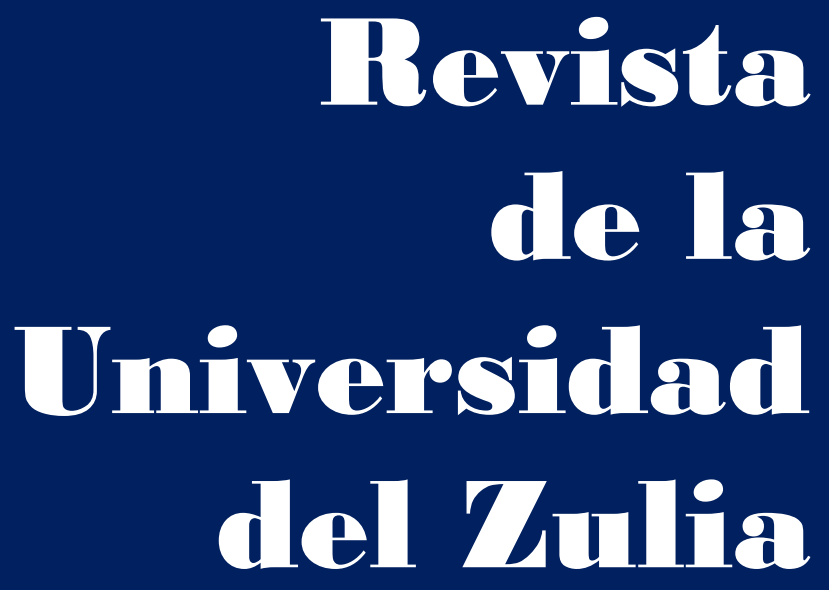

Fundada en 1947

por el Dr. Jesús Enrique Lossada

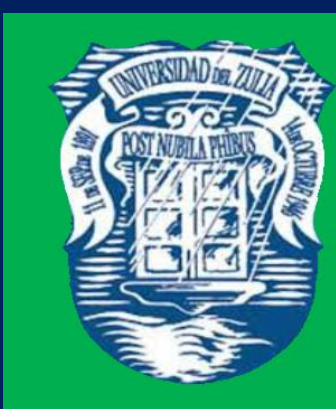

Ciencias del

Agred

Ingemieria

y Teenología
Añต 12 No 32

Enero - Abril 2021

Tercera Época

Maracailbo-Venezuela 


\title{
The issue of the information technology and technical terminology translatability from English into Russian: the typology and the nominative density levels
}

\author{
Natalia Bobrova * \\ Anton Lebedev ** \\ Larisa Tsybina *** \\ Iuliia Pinkovetskaia ****
}

\begin{abstract}
The 2lst century is characterized by its rapid scientific and technological advancement. Digital and technical inventions have resulted in computer globalization which caused the necessity of adequate translation of different kinds of English-language technical documentation, manuals, software products, etc. The article deals with the recent tendencies in translation and interpretation studies showing increasing interest to the ways English scientific and technical texts are rendered into Russian. The article considers the peculiarities of translating the scientific and technical vocabulary in the information technologies sphere and provides a typology of the English terms. Non-equivalent vocabulary is considered to be the most serious communication challenge. The authors identify the basic typical features of the computer discourse vocabulary, analyze the correlation between its nominal density and translatability level. The findings indicate that the ratio between the nominal density and translatability level of linguistic concepts is inversely proportional. The academic originality of the study involves the classification of technical and computer terms, as well as comparing nominal density and translatability levels. The article focuses on the most applicable English-language computer terms translation techniques, such as calquing, substantiation, generalization, semantic development, descriptive translation, antonymic translation, replacement and transformation of parts of a sentence. Pointing out that both linguistic and extralinguistic factors affect the translation solution choice, the authors believe that the correct approach to the translation process guarantees a successful intercultural communication.
\end{abstract}

KEYWORDS: information and computer technologies; scientific and technical vocabulary; nonequivalent vocabulary; terms; peculiarities of translation; nominal density; level of translatability; linguistic and extralinguistic factors.

*Department of the English Language for Professional Communication, Foreign Languages Faculty, N. P. Ogarev's Mordovia State University, Saransk, 430005, Russia. ORCID: https:/orcid.org/0000-0002-97192170.

**Department of the English Language for Professional Communication, Foreign Languages Faculty, N. P. Ogarev's Mordovia State University, Saransk, 430005, Russia. ORCID: http://orcid.org/0000-0002-19275595

*** Department of the English Language for Professional Communication, Foreign Languages Faculty, N. P. Ogarev's Mordovia State University, Saransk, 430005, Russia. ORCID: http://orcid.org/0000-0001-67305077 .

****Department of the Economic Analysis and State Management, Institute of Economics and Business, Ulyanovsk State University, Ulyanovsk, 432000, Russia. ORCID: http://orcid.org/0000-0002-8224-9031. Email: pinkovetskaia@gmail.com

Recibido: 09/09/2020

Aceptado: 05/11/2020 


\section{La cuestión de la traducción de la terminología técnica y la tecnología de la información del inglés al ruso: la tipología y los niveles de densidad nominativa}

RESUMEN

El siglo XXI se caracteriza por su rápido avance científico y tecnológico. Las invenciones digitales y técnicas han dado lugar a la globalización de las computadoras, lo que provocó la necesidad de una traducción adecuada de diferentes tipos de documentación técnica, manuales, productos de software, etc. en inglés. El artículo trata de las tendencias recientes en los estudios de traducción e interpretación que muestran un interés creciente por la forma en que los textos científicos y técnicos en inglés se traducen al ruso. El artículo considera las peculiaridades de traducir el vocabulario científico y técnico en el ámbito de las tecnologías de la información y proporciona una tipología de los términos en inglés. El vocabulario no equivalente se considera el desafío de comunicación más serio. Los autores identifican las características básicas típicas del vocabulario del discurso informático, analizan la correlación entre su densidad nominal y su nivel de traducibilidad. Los resultados indican que la relación entre la densidad nominal y el nivel de traducibilidad de los conceptos lingüísticos es inversamente proporcional. La originalidad académica del estudio implica la clasificación de términos técnicos e informáticos, así como la comparación de densidad nominal y niveles de traducibilidad. El artículo se centra en las técnicas de traducción de términos informáticos en inglés más aplicables, como cálculo, fundamentación, generalización, desarrollo semántico, traducción descriptiva, traducción antonímica, reemplazo y transformación de partes de una oración. Al señalar que factores tanto lingüísticos como extralingüísticos afectan la elección de la solución de traducción, los autores creen que el enfoque correcto del proceso de traducción garantiza una comunicación intercultural exitosa.

PALABRAS CLAVE: tecnologías de la información y la informática; vocabulario científico y técnico; vocabulario no equivalente; condiciones; peculiaridades de la traducción; densidad nominal; nivel de traducibilidad; factores lingüísticos y extralingüísticos.

Introduction

The modern conditions imply the rapid growth of information and computer technologies that serve as a communicative and informative sphere and encompass all the areas of professional and everyday life in general. The world of IT and multimedia creates the so-called "reality-within-reality" with its own moral, informal and even legal norms. The innovative technological advances create a "techno-sphere" which is transcendent, accessible and exists trans-nationally. A digital device is no longer a discrete unit existing 
within its own technological and data limits, but a workstation connected with the other users via network. The development of the digital currency and online advertising makes the "techno-sphere" an economic factor to be dealt with; it also possesses the certain cultural and even political influence: "ban" and "unfriend" policies become a widely discussed issue.

The specific significance of the IT and multimedia development has recently become additionally relevant due to the pandemic restrictions and further "digitization" of the educational space. While helping to provide relatively healthy, epidemically safe and productive academic environment, the Internet-based education has become a point of debate - whether it is valid only as a supplementary tool or can completely substitute the traditional in-classroom format. Nonetheless, Russian educational institutions and experts need profound awareness of the innovative technical and multimedia advances. This requires the appropriate and valid translation techniques, as well as the development of the national software and hardware products. They are mostly accompanied by the Englishlanguage documentation and manuals, as well as all communication between specialists in this field is also carried out mainly in English. Thus, substantial translation work is to be done; the issue of English computer vocabulary adequate translation is becoming increasingly widespread both for programmers and computer technology developers, as well as for non-professional PC users. Some people believe that such words pollute the language, while others suggest that they are an indicator of the high level of science and technology development. The terms that were previously used in the professional speech of IT experts have become widespread both in the professional field and everyday life of modern society. Despite the vast number of works in the field of general terminology, translation theory and lexicography, accurate and concise translation of IT terms is gaining its relevance.

The English language is widely recognized as the so-called "lingua franca" in multiple spheres, including law, academic activities, engineering and information technology (IT). It is justified not only by the linguistic criteria per se, but can also be explained by extralinguistic factors: English-speaking countries are the creative source of the latest technological advances and the basis of the world's largest innovation clusters - in particular, the California Silicon Valley comprising the headquarters of such high-tech 
companies as Adobe, AMD, Apple, Electronic Arts, Facebook, Google, Hewlett-Packard, Intel, Nvidia, Symantec, Yahoo, Xerox. The high level of globalization and cooperation in the field of technology results in the urgency of overcoming language barriers, as well as filling linguistic gaps in the absence of certain lexical units in the "recipient" (e.g., Russian) language. By acquiring the competence of terminology and nomenclature, as well as the appropriate language proficiency, IT professionals are able to seamlessly share their expertise, experiences and innovations.

Accordingly, this requires not only the specific professional abilities, but also the linguistic skills and competences that the experts in a given IT sphere need to master. As stated by M. I. Murneva, N. A. Shestakova, E. V. Samoilova (2018): "... the specificity of the English language lies in the fact that the most important role in its mastering is played by training and the use of material in the act of communication, which takes time". The relevance of the research is evidenced in the development of the subject area that rapidly permeates our everyday life; therefore, there is a constant growing need of translation and communication in the IT sphere. The development of technologies requires not only technical skills, but also linguistic comprehension - in particular, systematization of terminology, publishing of dictionaries, development of specific educational programs etc. The peculiarities of IT nomenclature are as follows: accuracy, condensation of meaning (high nominative density), logics, consistency and brevity.

The academic significance of the research is explained by the analyzing of the correlation ratio between the level of translatability and nominative density; the proposed classification of IT, technical concepts and nomenclature are also of great interest. The work is aimed to identify the main features characteristic of this vocabulary, as well as to analyze the relationship between its nominative density and the level of translatability. To achieve this goal, the authors set the following objectives:

1) to assess the overall significance of the terminology when translating technical texts;

2) to identify the main types of information technology vocabulary;

3) to classify these types according to their level of translatability and nominative density; 
4) determine the relationship, correlation and ratio between the degree of translation complexity and nominative density.

The process of the research included the methods of vocabulary, the syntactic and comparative translation analysis. The research material involved the extracts from the technical texts and individual lexical units typical for the field of information technology excerpts from instructions and textbooks, as well as examples from the authors` translation and teaching practices. The results of the research could be used in the development of the courses on technical translation, as well as practical materials for interpreters in the computer, technical and information fields.

\section{Literature Review and Discussion}

The issue of the technical texts translatability is reflected in the works of many Russian and foreign researchers: J. Byrne (2006), I. Blank (2000), L. I. Borisova (2005), P. A. Elin (2012), B. N. Klimzo (2017), I. L. Komleva (2009), L. A. Konyaeva (2015), O. D. Mitrofanova (1973), A. L. Pumpyanskiy (1965), N. Ravzhaa (2009), V. I. Sidorova, E.V. Tikhonova, L.K. Kondratyukova (2011), R. Stoltse (2009). The scholars raise the question of the translation difficulties, reveal a number of lexical features of the English-Russian academic and technical translation, consider the trends in the development of the so-called "technical English". They study and analyze the issues of dynamic equivalence, translatability levels, general translation techniques and specific translation areas based on the hand-on experience and case studies.

Thus, I. L. Komleva (2009) introduces the term "computer language" and offers the following definition: "... a specific terminology that is being formed in the subject area, technologically related to the production of personal computers and software". At the same time, the researcher highlights the following thematic areas of the computer terminology development: general information about digital devices (creation, production, models, functions); hardware and equipment; software (including operating systems); programming languages, creation of software products; solving computational problems; information, communication and multimedia technologies.

Considering the problem of "neologization" (neologisms formation) and codification of terms, N. Ravzhaa (2009) analyzes a number of principles, "on the basis of which the 
Russian-language technical terminology is formed in a particular area or industry": the principle of translation (simple transfer of the semantics of certain lexical units: antivirus, homepage, speakers, resolution); the priority of the native language (edit, paste, booting), that is, the rules of the Russian vocabulary, lexis and grammar are given priority); the principle of common, "everyday", vocabulary (mouse, web, basket); the principle of integration (the transition of terms from one area of knowledge to another: for example, "social network" is not merely the Internet technology, but a sociological concept as well). According to A. V. Lebedev (2018), "the Internet space is a source of formation of a new culture, including the latest linguistic concepts".

The researchers V. D. Tabanakova and A. B. Kutuzov (2007) state that “... the computerization progress necessitates the adequate translation. Nowadays, the issue of translating English digital terminology into Russian is especially relevant. It is necessary and vital for technical documentation and literature, software interface and lexicographic work". However, they also note that "the difficulty of texts translation, in the field of information technology in particular, is that many computer terms refer to non-equivalent vocabulary, that is, they do not have regular correspondences in Russian (except for dictionaries' descriptive articles)".

V. V. Makhova (2015) lists the criteria for the successful and valid translation as a result of the interpretation process: "one cannot avoid the fact, that when performing an academic text translation, the following elements are to be taken into account: the accuracy of information inherent in it, the argumentation persuasiveness, the logical presentation sequence, the laconic form, consistency, as well as a high degree of information density due to the number of terms in the text". The authors of this paper agree that when working with technical texts, one should take into consideration the prevalence of various types of abbreviations, the preference of some syntactic phrases over others, the peculiarity of the grammatical constructions` translation.

The issue of "translation decision" and "interpreter`s creativity" is studied by multiple Russian and Post-Soviet researchers. L. L. Nelyubin (2003) states that the translation solution plays an important role when interpreting scientific and technical literature, one needs to find the optimal choice of synonymous substitution for a specific translation unit in the translating language. V. I. Karaban (2003) expresses similar views 
indicating that "one of the most difficult aspects in translation is the choice of one lexical element from a number of synonyms", justifying this by the fact that "synonyms are often characterized only by insignificant semantics and stylistics which the translator needs to know in order to make the right interpretation decision". N. E. Bobrova (2004) points out that "having basic knowledge in the professional field a future specialist needs to possess analytical thinking".

The study by E. F. Skorokhodko (1963) analyses the peculiarities of scientific texts touching upon special technical terms: "A large number of special terms in the text, especially newly appeared (neologisms), creates significant difficulties in translation practice". Neologisms formation is in focus of the other works. In addition, A. A. Veyze, N. B. Kireev, I. K. Mironchikov (1997) concentrate on neologisms as the most considerable difficulty when working with scientific and technical literature, since most of them are absent in dictionaries. The problem of polysemantic words is pointed out by R.F. Pronina (1989): "despite a huge number of technical terms, the language of scientific and technical literature includes a large percentage of common words and phrases, and a significant part of common lexis is polysemantic words".

The concise and precise wording of the translation is in focus of L.N. Porokhovnik's research (1992). The author stresses that the interpretation is directly dependent on the personal qualities of the translator, as well as "requires knowledge in the specific field of the translation". L. S. Barkhudarov (1975) suggests that the most widespread and generally accepted concept is the interpretation of non-equivalent vocabulary as lexical units that have neither full nor partial equivalents among the target language lexical units. The scholar (Nelyubin, 2009) states that non-equivalent vocabulary traditionally includes culture-bound terms, neologisms, anthroponyms, toponyms, zoonyms and other proper names, as well as temporarily non-equivalent terms and accidentally non-equivalent words, or "accidental gaps".

Dealing with the English language computer terminology translation and the ways of non-equivalent vocabulary cultural adaptation are considered in the survey by M. A. Bolotina and A. A. Smirnova (2018), as well as some types of non-equivalent vocabulary in the English discourse and the ways of translating lexical items into Russian. The researchers claim that the main types of non-equivalent vocabulary are divided into three 
groups: referential-non-equivalent, pragmatic-non-equivalent and alternative-nonequivalent vocabulary. For computer-information discourse referential-non-equivalent vocabulary is the most typical, namely terms, author's neologisms and words of broad semantics.

The translation of IT and technical nomenclature has been a study focus of many international researchers dealing with translatability into their local languages, as well as the implementation of technical and online advances into the professional and educational spheres. For instance, S. Göpferich (2018) analyzes the linguistic measures of standardization that consists of the introduction of a standardised terminology, compliance with a style guide and the use of a controlled language (CL). Inter alia, CLs are illustrated by the rules of the Simplified Technical English (STE). The study "Leveraging bilingual terminology to improve machine translation in a CAT environment" (Arcan et al., 2017) deals with the extraction and integration of automatically aligned bilingual terminology into a Statistical Machine Translation (SMT) system in a Computer Aided Translation scenario. The information technology nomenclature is compared and tested in English, Italian and German and draws the conclusion of the significant improvement of the system results, especially compared to the widely-used XML markup approach. S. Wentao (2016) from Linyi University of Shandong, China emphasizes the significance of computer English, the manifestation of the linguistic features, IT English vocabulary and syntax characteristics and the peculiarities of computer English-Chinese translation skills.

In the survey "Evaluating Automatic Term Extraction Methods on Individual Documents" (Bašić et al., 2019), the researchers state that ATE is implemented in many tasks, including Computer Assisted Translation. The authors study the results of transfer to document-level ATE and "evaluate 16 state-of-the-art ATE methods on full-length documents from three different domains, on both corpus and document levels". The similar issue is discussed in the study by V. Bilic (2020) on the online computer-assisted translation classroom, that is a means of teaching how to use the latest translation technology through hands-on remote software use and collaborative translation exercises. In teaching the prospective technical interpreters, the scholar draws on process-oriented approaches to translator training and the method of cooperative translation. 
Digital technologies and the terminologized lexis are also in focus of the comprehensive research by V. Celiešienè and S. Juzeleniene (2020) who state the aim of their article: to reveal semantic motivation of terminologized Lithuanian and English computer lexis, drawing the conclusion that close similarities between central meanings of specific English and Lithuanian words caused the development of new terminological meanings related to information technologies.

Authors (Nzomo et al., 2016) study the multilingual information retrieval and use within the framework of perceptions and practices amongst bi- or multilingual academic users. Having analyzed the issue by surveying bi- or multilingual students recruited from a Canadian university and a community college both located in London, Ontario, the authors conclude that achievements of technology have alleviated some of the linguistic related challenges while searching for information online. However, language barriers still exist for some students, especially at the query formulation stage. The issue of Speech-to-speech translation (S2ST) and word-level equivalence is dealt with by authors (Do et al., 2017). The system is designed to remove barriers in cross-lingual communication, including the technical and programming area. The conventional S2ST systems substantially and appropriately convey the linguistic meaning of speech, but partially lose paralinguistic information expressing other speech characteristics (i.e., emotion or emphasis). The paper proposes a method to translate this paralinguistic data, focusing on emphasis and intonation, studying the components that can accurately translate emphasis using all acoustic features of speech. The listening tests indicate that the respondents could identify the emphasized words with $87.8 \%$ accuracy, and that the naturalness of the audio material was preserved.

Thus, there is a common agreement that a translator dealing with IT-terminology is to comprehend the peculiarities of both English and Russian nomenclature. The linguistic knowledge should be accompanied by the competence in a subject area; this is critical for coping with the difficulties of translating technical terms specific to the field. Inconsistent, incorrect and inappropriate use of terms distorts the meaning of the original information message and impedes communication, resulting in data loss. Since contemporary companies and industrial establishments consider the consistency of terminology as the core of business communication, they are seriously involved in terminology work, clarifying 
terms that can lead to confusion, and ensuring the uniformity of the terminology used in practice. These institutions develop specialized terminology databases containing not only industry-specific terminology, but also corporate abbreviations and intercompany terminology that are specific for certain companies.

Basing on the above-mentioned concepts and researchers`notions and viewpoints, one could single out several major types of lexical units related to information and technical terminology.

\section{Findings}

\section{2.l. Neologisms}

Regarding the translation of original sources into the Russian language, the main difficulty is posed by neologisms. The translation solution plays an important role when dealing with scientific and technical literature; an interpreter would need to find an optimal synonymous substitution for a specific translation unit in the translating language. Computer vocabulary in English (along with youth slang, terminology of art, journalistic texts, and academic nomenclature) is the most important source of neologisms in the sphere of the Russian linguistics. Along with the production of a technical innovation, these lexical units emerge in the English language and then are transferred into Russian, becoming the common-use lexemes in everyday life, while the term already existing in the language is replaced.

Consequently, the emergence and widespread dominance of computer technology in Russia resulted in the replacement of the following words: calculator - computer, digital printing device - printer, etc. This trend is driven by the tendency to form a unified international terminology, as well as the ease of its application in real communication situations. At the same time, already capacious English words are simplified and "vulgarized" which leads to the appearance of the so-called "computer slang" - "hard" (hard disk), "soft" (software), "mat" " (Russian "mother", 'motherboard), "fiksit" (from the word fix repair), "drova" (Russian "firewood", drivers, programs to ensure the operation of devices) and many others.

\subsection{Contextual Terminology}


Another feature of computer and technical terminology is its highly specialized nature and contextuality. The main task in its translation is the definition of the discourse, sphere and area translation, as well as an adequate transfer of meaning, taking into account the semantics of lexemes. If some computer lexical units can be translated by the method of transferring an unambiguous equivalent in about the same for all spheres in a way (tablet, device, desktop, laptop, personal computer), in other cases the equivalence is contextual (variant) and the contextual translation is preferred.

In particular, different words denoting seemingly similar concepts can vary significantly in context. For example, translating requires the knowledge how to distinguish the words "storage" and "memory" and how these notions are fundamentally different, which denote computer memory. In the first case, most likely, one implies a data storage device / drive, while the word "memory" more frequently denotes random access memory (RAM). In this case, both words can be translated as pamayt "memory (device)". Another example of contextuality when translating technical terms is the word "deadlock", which can be translated as "stalemate" in the general sense, but has at least two meanings in the digital environment - "program freeze", "glitch". In the English version, the definition of deadlock is much shorter while in the process of translating into Russian, it seems critical to avoid ambiguous interpretation.

This leads to the identification of three main principles when dealing with contextual terminology translatability: 1) the correct definition of the concepts expressed by a term could be done provided that a translator acquires certain specialized knowledge; 2) despite the fact that terms are characterized by a specific meaning in concrete contexts and have a tendency to be mono-semantic, they cannot be considered as absolute semantic units, since a number of terms with a certain technical meaning can change their content depending on the field and context in which it is used; 3) correct interpretation of terminology units requires the knowledge of terms morphological structure, their specific semantic meaning, as well as the main types of terms and phrases.

Regarding their structure, all the terms can be divided into the following categories:

1. "Simple" type - e.g. application, decode, panel - which are characterized by the same term system and relative unambiguity; 
2. Multi-semantic type - e.g. pagefile, paint-brush, fault-tolerant - that can be differently used in various contexts and have different meanings in some branches of the same scientific or technological sphere. For instance, deadline - a date within each assignment by which submission, review and approval should be completed (IT sphere), deadline equipment awaiting repair or maintenance (oil refining industry). Thus, a translator is expected to pay attention to the semantic environment when translating the homonymous terms to avoid incorrect and inappropriate equivalents and interpretations.

3. Word combinations - e.g. file allocation table, call distribution, scale integration - that are the most difficult for translation since they consist of two and more separate units. The main component is the last word, and the determining element is the penultimate word, phrase or compound term.

This indicates that the referred technical style under consideration should be characterized by concreteness and unambiguity. The following terms also require taking into account the contextuality in translation: monitor ("Monitor" or "checking, tracking"), input ("input" or "information induction"), computing ("calculation" or "computer network"), data mining ("mining" or "data extraction") etc.

\subsection{Translation Misinterpretation (i.e., "Translator`s False Friends")}

In other cases, only unambiguous equivalents should be considered - the terms may outwardly resemble widely used words (the so-called "false friends of the translator"). This leads to the misinterpretation of the terminology based on linguistic similarities. Consequently, "waking up" has nothing to do with morning routines but refers to "waking up" of the computer system; battery life is not how long the battery can operate without charging but the level of battery deterioration; frame rate is not the "level of framework" but rather the digital terminology; box is a "window", not a physical "box"; bar - "panel, tab ", not" hash "and so on. When translating into Russian, additional verbs and auxiliary words can be introduced, if necessary, to comply with the language norm, which is an integral part method of compensation for translation: e.g., Code-Less - "reduction of the amount of code (program)"; Physical Security - not - "ensuring security at the physical level"; Firewall Virus Detection - "detection of virus programs using a firewall". 


\section{4. "Imagery" Terminology}

The technical and IT-vocabulary is commonly associated with the units that create an image providing users with a mental picture. This implies the wide implementation of phraseological units - expressions which are lexically indivisible, compositionally and structurally fixed, integral in meaning and reproduced in the form of a ready-made speech units. L.V. Tsybina and D.G. Garan'kin (2020) states the properties of phraseological units: reproducibility, sustainability, idiomaticity, inseparability, belonging to the nominative inventory of the language. The distinctive features of digital and IT-terminology additionally include metaphorical nature and imagery. For instance, users and developers view the sphere of computer technology as representing "intelligent creatures" that possess memory, language and even become "infected" with a "virus". The other illustrations include the terms "mouse" and "Windows" showing their similarities to the represented images. A device for regulating the movement of the cursor has the image of a mouse, while the name of the Windows program is associated with the way of providing information in the form of windows on a computer screen (graphic user interface).

Professional terminology is frequently associated with jargon (estimated to constitute up to $40 \%$ of IT nomenclature). The thesaurus of the computer and information technology sphere is borrowed from general English; consequently, the technical vocabulary is used not only in professional environments, but also in everyday life, both by specialists and users of all ages and professions. As one can observe from the previous examples and illustrations, in some cases, computer vocabulary is characterized not only by imagery, but even some emotional coloring and metaphor, which is especially characteristic of the American technical discourse (firewall - literally "a wall of fire, an insurmountable obstacle"; hosting - literally "placement, to be the master of smth."; web - "cobweb"; network - "fishing nets" etc.).

While preserving the original semantics as much as possible, a translator has to dwell on a more neutral equivalent, omitting stylistically or overly "emotional" or "imagery" elements. For instance, V. I. Sidorova, E.V. Tikhonova and L. K. Kondratyukova (2011) offer the following example: Dial up FireWalling with Free BSP could be rendered as "building a firewall on a dial-up communication channel using Free BSP". The word "bottleneck" (literally - "neck of a bottle", "narrow passage", "traffic jam"), which in the technical sense 
conveys the meaning of a resource limiting the production capabilities of the entire production process, i.e., equipment with the lowest bandwidth, the inability of a separate segment of the system to cope with a given volume of work, which slows down the execution of subsequent operations by other segments of the system" (Tanenbaum \& Herbert, 2015). Accordingly, the short and concise phrase "CPU bottleneck" is translated as "the system downtime associated with CPU overload". Another example is the phrase "Split-hair accuracy", which draws a specific image and mental picture to convey the meaning of precision.

\subsection{Abbreviations / Acronyms}

Like other areas and fields, technical and computer terminology has a tendency to abbreviations, which is associated with the need to quickly express complex and capacious concepts and notions. There are a number of generally accepted and widespread abbreviations that are common for the majority of computer or mobile device users: WWW - World Wide Web; FAQ - Frequently Asked Questions; QR Code - Quick Response Code. In a highly specialized text, there may be specific abbreviations that are understandable to a specialist or an expert in a given field or a subject area: SSD - Solid-State Drive; API Application Program Interface (software interface); ISP - Internet Service Provider; DNS Domain Name System. Certain abbreviations or acronyms are actively used in speech, while their complete explanation and expansion is not widely known. For instance, "SIM card" SIM - subscriber identity module; CD-ROM - Compact Disk Read-only Memory - a kind of CD with recorded with read-only data; JPEG - Joint Photographic Experts Group - image format. According to N. I. Rokunova and O. V. Slugina (2018) the learning of these lexical units demands and requires a "contextual approach".

\subsection{Attributive Phrases}

This type of collocations under consideration constitutes attributive constructions that point to the properties, qualities and characteristics of various complex phenomena. At the same time, attributive constructions with an adjective attribute can be distinguished as subtypes (attributes - adjectives); attributive constructions with a verb attribute; attributive constructions with a substantive attribute (attributes are nouns); attributive collocations with internal predication (attributes - phrases or sentences). The need for 
attributive word combinations is associated with the overall high nominative density of English language concepts, as well as with the tendency to compression, capacity and accuracy. For instance, device charge status light defect is a non-working status indicator device charge; equipment medical device interference guideline - equipment manual (index) on the impact on the operation of medical devices; nearly total self-management system - a system with almost complete self-management, etc. The examples indicate that the translation of such attributive constructions is carried out by careful analysis of the interdependence and interrelation of their structural elements and components. In this case, the major semantic core is usually located at the end of the phrase, respectively, the attributes are translated, starting with the closing elements.

\section{The Nominative Density Ratio and Translatability Levels of IT-Terminology}

Nominative density is defined as "the degree of detail of the linguistic representation of a certain conceptual space, detailing the designated fragment of reality, multiple variable designations and complex semantic shades of a notion under consideration" (Popova \& Sternin, 2007), it increases as the level of translatability decreases (reverse ratio). At the same time, the level of translatability denotes the degree of equivalence (unambiguous, variant, zero types) in translation, as well as the level of linguistic and cultural adaptation of IT and technical concepts. For example, neologisms often have a high degree of nominative density, but their mere existence is justified by the lack of translatability or practical reasons (in particular, compression). Attributive constructions assume a sufficient degree of unambiguity (respectively, have a lower nominative density), while their translatability is higher.

The following diagram represents the typology of lexical units related to information, computer and technical spheres. The basic types of lexical units discussed above were taken as a basis, related to information technology terminology. There is also a certain correlation between the degree of nominative density and the level of translatability. 


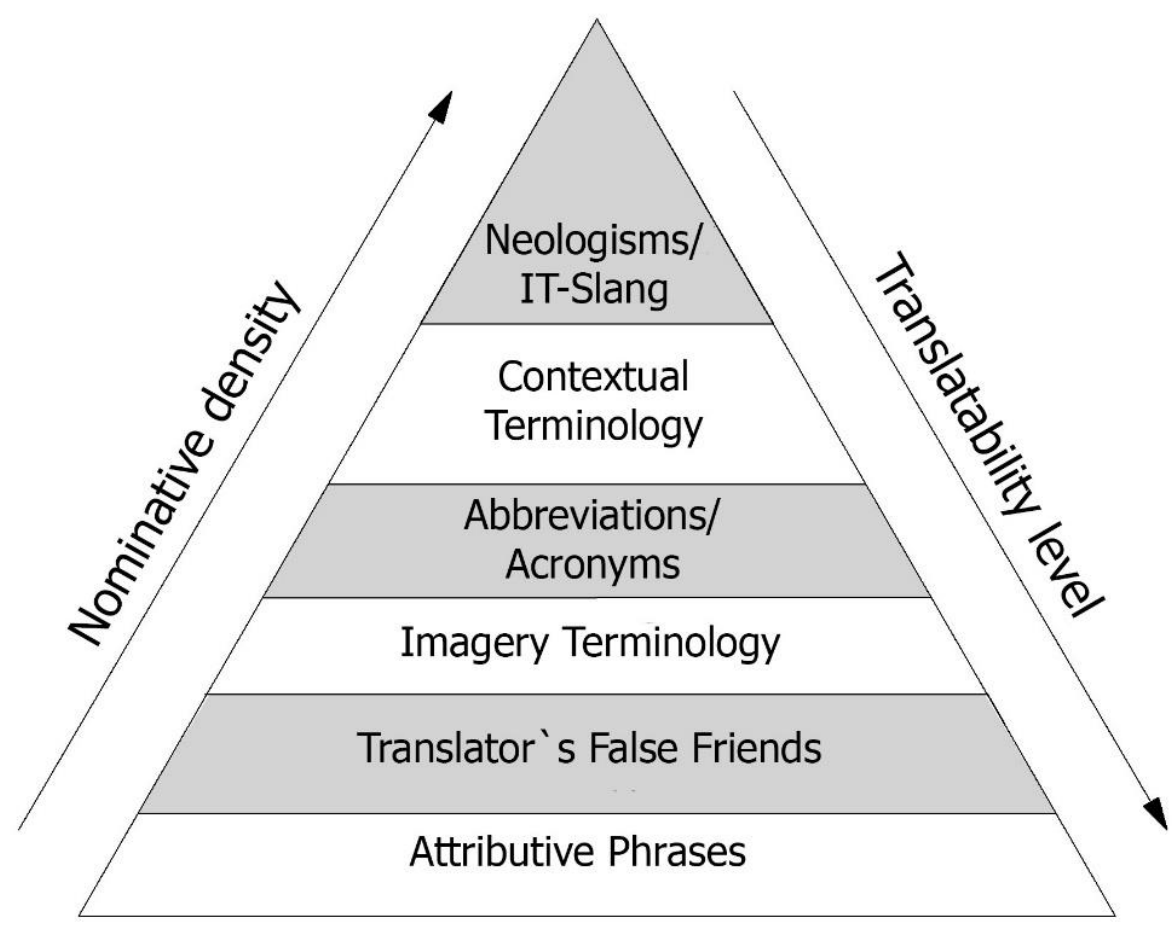

Based on this diagram, the following observations can be made:

1) translation of technical texts is especially complicated and challenging, since this area has an impressive volume and contains many complex, as well as highly specialized terms related to all of the stated categories;

2) there is an inverse proportionality (ratio) between the nominative density of terminological concepts and the levels of their translatability;

3) the increasing nominative density leads to the "archiving" of the concept, which makes the process of extracting and reconstructing it in the native language even more challenging;

4) approaching the top of the diagram ("the pyramid"), the neologization (neologisms formation) process takes place, which is justified by the high nominative density and low level of translatability;

5) at the "base of the pyramid" there are those types of terms that have a low nominative density (due to attribution, figurativeness and unambiguous equivalence). Despite the high level of their translatability, translation may still be challenging. 
Conclusion

The globalization era increasingly reveals the importance of translation in every sphere of life. Close interaction, collaboration and integration of countries, companies and individuals across the world is the result of rapid pace of science and technology development. Moreover, the rapid development of different fields of science and technology enhances the importance of scientific and technical translation. The cyber world existence proves the relevance of research on methods of translating English-language computer terms. It has resulted in borrowing of a considerable number of technical neologisms into the Russian language, especially in IT and Internet areas. This process is continuous, inevitable and unstoppable.

Thus, the computer discourse consisting of non-equivalent vocabulary can become a serious communication challenge. While translating various types of vocabulary, one should focus on the diverse components of communication that are relevant in a given pragma-linguistic and cultural context. The reference function (i.e., an idea behind the lexical unit) is relevant for the terms and words of broad semantics translation. To achieve the appropriate and correct equivalence, various translation transformations are used: "calque" method, descriptive translation, transcription and transliteration, substantiation and lexical omission. The interpretation models in the translation process include: situational (denotative), transformational, semantic, and psycholinguistic.

It should be pointed out that both linguistic and extralinguistic factors influence the translation solution choice; consequently, knowledge of linguistics and a substantial amount of background (environment, reality) data are the key to professional translation. Thus, a translator is required to rely on general erudition, possess the skills to search for information, use linguistic knowledge in the field of a particular field and creative approach. The major task is to choose the most appropriate equivalent for broad semantics words basing on context, as well as to transfer what an author intended to say without changing the lexico-semantic meaning of words. Contextual and hyponymic translation, the method of assimilation is most frequently used when translating broad meaning lexemes.

Having considered some of the features of the IT and technical terms translatability, the following conclusions can be drawn: 
1. Translation in the field of IT occurs almost immediately after (or even in the process of) the development of innovative technologies. This requires the earliest possible study of existing terms and the competent introduction of new concepts into local languages.

2. The research identifies the different types of terminology in the field of IT; their classification and typology indicate the demand of further research on the issue of translatability, as well as the direct study of the subject areas.

3. The distinctive feature of academic and technical vocabulary is a large number of specialized terms and abbreviations. As the field of information technologies is constantly developing, their number is increasing. At the same time, different degrees of translatability determine the complexity of translation and the need for high competence required of the translator.

4. The relationship, correlation and ratio between the nominative density and the degree of translatability of the IT linguistic concepts is inversely proportional serving as the evidence of the complexity in the transmission of lexical units from one language to another.

\section{References}

Arcan M., Turchi M., Tonelli S. \& Buitelaar P. (2017). Leveraging bilingual terminology to improve machine translation in a CAT environment. Natural Language Engineering, 23(5), 763-788. Available at: https://doi.org/ 10.1017/S1351324917000195 (accessed 13.01.2020).

Barkhudarov L.S. (1975). Language and translation, International relations, Moscow.

Bašić B.D., Buljan M., Šnajder J., Šajatović A. (2019). Evaluating Automatic Term Extraction Methods on Individual Documents. Proceedings of the Joint Workshop on Multiword Expressions and WordNet (MWE-WN 2019). Florence: Association for Computational Linguistics, 149-154. Available at: https://www.aclweb.org/anthology/W19-5118/ (accessed 04.01.2020). DOI: 10.18653/vl/W19-5118.

Bilic V. (2020). The online computer-assisted translation classroom. The International Journal for Translation \& Interpreting Research, 12(1), 127-14l. Available at: https:/www.transint.org/index.php/transint/article/view/1028 (accessed 06.01.2020). DOI : 10.12807/ti.l12201.2020.a08.

Blank I. (2000). Terminology extraction from parallel technical texts. Parallel text processing. Dordrecht, Springer, 237-252. 
Bobrova N.E. (2004). On the translation issue as a method of teaching language for special purposes. Humanitarian research: tradition and innovation. Collection of scientific and methodological works. Saransk, 163-167.

Bolotina M.A., Smirnova A.A. (2018). Translation of non-equivalent vocabulary in the localization of computer games. Bulletin of the I. Kant Baltic Federal University. Philology, pedagogy, psychology, 1, 20-28.

Borisova L.I. (2005). Lexical features of the English-Russian scientific and technical translation: theory and practice of translation. Moscow, NVI-TEZAURUS.

Byrne J. (2006). Technical translation: Usability strategies for translating technical documentation. Dordrecht, Springer.

Celiešienė V., Juzeleniene S. (2020). Semantic motivation of the terminologized lexis in the field of digital technologies. Journal of Teaching English for Specific and Academic Purposes, May. Available at: https://yandex.ru/search/?from=chromesearch\&clid=2242348\&text=htthttps\%3A\%2F\%2F www.researchgate.net\%2Fpublication\%2F341413771_SEMANTIC_MOTIVATION_OF_TH E_TERMINOLOGIZED_LEXIS_IN_THE_FIELD_OF_DIGITAL_TECHNOLOGIES\& $\&$ lr=42 (accessed 12.01.2020). DOI: 10.22190 / JTESAP2001031C.

Do Q.T., Toda T., Neubig G., Sakti S. \& Nakamura S. (2017). Preserving Word-Level Emphasis in Speech-to-Speech Translation. IEEE/ACM Transactions on Audio, Speech, and Language Processing, 25(3), 544-556. Available at: https://ieeexplore.ieee.org/document/7792638 (accessed 11.01.2020). DOI: 10.1109/TASLP.2016.2643280.

Elin P.A. (2012). Peculiarities of translation of scientific and technical papers. Scientific periodicals: problems and solutions, 4(10), 11-13.

Göpferich S. (2018). Standardisation of Language and Communication. Handbuch Sprache in Organisationen. Berlin, Boston: De Gruyter. Available at: https://oi.org/10.1515/9783110296235-010 (accessed 12.01.2020).

Karaban V.I. \& Mays J. (2003). Translation from the Ukrainian language into the English language. Vinnytsia, Nova Kniga.

Klimzo B.N. (2017). The technical translator's craft: about the English language, translation and translators of scientific and technical literature. 4th ed. Moscow, R.Valent.

Komleva I.L. (2009). Principles of formation of Russian computer terminology, Moscow.

Konyaeva L.A. (2015). Some of the difficulties of scientific and technical translation. Translation and comparative linguistics, 11, 50 -54.

Lebedev A.V. (2018). Internet technologies in teaching foreign languages as a vector of development of higher education. Humanities and education, 9(2), 64-69. 
Makhova V.V. (2015). Semantic analysis of scientific and technical texts as a way of forming foreign language competence in the field of professional communication (on the example of teaching students of non-linguistic universities). State South-West University, Kursk.

Mitrofanova O.D. (1973). The language of scientific and technical literature. Moscow, Publishing house of Moscow University.

Murneva M.I., Shestakova N.A. \& Samoilova E.V. (2018). Modern Technology of Teaching English at Non-Linguistic Faculties: Science or Art? Philological Science. Issues of Theory and Practice. Tambov, 3-2 (81), 415-418.

Nelyubin L.L. (2009). Introduction to translation technique (cognitive theoretical and pragmatic aspect). Moscow, Flinta.

Nelyubin L.L. (2003). Explanatory translation dictionary. Moscow, Flinta, Nauka.

Nzomo P., Ajiferuke I., Vaughan L. \& McKenzie P. (2016). Multilingual information retrieval \& use: perceptions and practices amongst bi/multilingual academic users. The Journal of Academic Librarianship, 42(5), 495-502. Available at: http://www.sciencedirect.com/science/article/pii/S0099133316300969 (accessed 11.01.2020). DOI: https://doi.org/10.1016/j.acalib.2016.06.012.

Popova Z.D. \& Sternin I.A. (2007). Cognitive linguistics: monograph. Moscow, AST, Vostok - Zapad.

Porokhovnik L.N. (1992). Difficulties with industry terminology. Theory and practice of translation, 18, 65-73.

Pronina R.F. (1989). Manual for the translation of English scientific and technical literature. Moscow, Higher school.

Pumpyanskiy L. (1965). Manual for the translation of scientific and technical literature into English. Moscow, Science.

Ravzhaa N. (2009). Teaching Mongolian students-non-philologists (programmers) reception and production of texts containing definitions of computer terms, Moscow.

Rokunova N.I. \& Slugina O.V. (2018). Basic approaches and principles of teaching English phrasal verbs to students of non-linguistic specialties. Bulletin of the Perm National Research Polytechnic University. Problems of linguistics and pedagogy, 4, 172-180.

Sidorova V.I., Tikhonova E.V., Kondratyukova L.K. (2011). English for postgraduate students: textbook. Omsk, OmSTU Publishing House.

Skorokhodko E.F. (1963). Questions of translation of English technical literature. Kiev, Kiev University.

Stolze R. (2009). Dealing with cultural elements in technical texts for translation. The Journal of Specialized Translation, 11, 124-140. 
Tabanakova V.D., Kutuzov A.B. (2007). Prolegomena to the denotative model of computer terms translation. Urgent problems of linguistics and terminology, Yekaterinburg, 38-40.

Tanenbaum E.S. \& Herbert B. (2015). Modern operating systems. St. Petersburg.

Tsybina L.V. \& Garan'kin D.G. (2020). Structural-Etymological Analysis of the English Phraseological Units in the Sphere of Sport with the Onym Component (by the Material of the English Language). Philological Science. Issues of Theory and Practice. Tambov, 13(1), 230-235. Available at https://doi.org/10.30853/filnauki.2020.1.46 (accessed 10.01.2020).

Weise A.A., Kireev N.B. \& Mironchikov I.K. (1997). Translation of technical literature from English into Russian: study guide, Minsk.

Wentao S. (2016). The Study of Computer English Language Characteristics and Chinese Translation Skills. Advances in Social Science, Education and Humanities Research, 85. Available at https://download.atlantis-press.com/article/25865393.pdf (accessed 09.01.2020). 